\title{
El Vaticano II. Un concilio \\ "generador de crisis" \\ con una agenda no escrita
}

\section{Aloysius Pieris, S. J. Sri Lanka}

\section{Introducción: "No pierdan el tiempo con el Vaticano II"}

\subsection{El consejo de Rahner a los jóvenes}

Con la perspectiva del tiempo, veo que fue un privilegio muy especial que mis estudios teológicos coincidieran con los años del Vaticano II (1962-1966), y sobre todo que los hiciera en uno de los lugares más pintorescos de Nápoles, a dos horas en el rápido, un tren de alta velocidad, de donde sesionaba el concilio, Roma. Alli conocimos en persona y en un ambiente de paz a algunos de los periti, los expertos, del concilio, que venían a pasar un fin de semana con nosotros para disfrutar del sol y de la belleza de la bahía de Nápoles o para gozar del panorama que el Vesubio ofrece a los visitantes. Entre estos sobresalla Karl Rahner, a quien invitaron oficialmente a pronunciar la lectio brevis - el discurso inaugural-, al comienzo del curso académico.

Recuerdo que en una de sus visitas informales se qued6 con nosotros durante el recreo, después de la comida, y nos hablo de forma espontánea sobre lo que estaba ocurriendo en el interior del concilio. La conversación fue muy iluminadora. Le preguntamos cuál debería ser nuestro papel en la implementación de los decretos conciliares. Respondió largamente, y comenzo con estas palabras muy sorprendentes: "jno pierdan el tiempo con el Vaticano II!”. A $e l$ sí le tocaba la tediosa tarea de explicar los decretos conciliares, justificarlos y fundamentarlos, en la tradición auténtica de la Iglesia. Le parecía necesario porque -como lo percibió proféticamente- para sus contemporáneos, es decir, la generación de gente mayor a la cual pertenecía, incluyendo a algunos de los obispos que firmaron los documentos, iba a ser casi imposible captar la perspectiva radicalmente nueva, desde la cual el concilio estaba formulando su mensaje. Si no se 
reconocía esa nueva orientación, decía, las enseñanzas del Vaticano II podrían ser mal interpretadas, pues se leerían desde los caminos trillados de la teología, y eso era, precisamente, lo que el concilio trataba de superar, por considerarla inadecuada.

Visto desde hoy, parece que Rahner ya prevefa el conflicto entre los tradicionalistas y los renovadores, en la lectura misma de las enseñanzas del concilio. $\mathrm{Y}$ es que los documentos del concilio iban a reflejar, en muy buena medida, compromisos y contradicciones, cosas ambas que sólo podían ser aclaradas desde la perspectiva global del mismo. De no ser así, se acabaría en una Babel, una gran confusión, juna verdadera barrera del lenguaje dentro de la Iglesia! El concilio, en efecto, abría nuevas perspectivas, pero no disponía de un lenguaje nuevo y coherente, capaz de comunicar esa novedad. Existía el peligro real de que el antiguo lenguaje, el que estaba siendo usado por el concilio, llevara con frecuencia a una interpretación contraria al nuevo espíritu, que soplaba en toda la Iglesia.

En este contexto, es bueno recordar que Juan XXIII, quien convocó el concilio, era historiador de la Iglesia, y por eso, era capaz de relativizar muchas "tradiciones" que enterraban a "la Tradición", a la cual el papa querfa que la Iglesia fuese fiel'. Las tradiciones obsoletas hablaban un lenguaje obsoleto, que ya no podía comunicar al mundo la buena noticia de Cristo y de su Iglesia, tomados ambos a una. Sólo el espíritu de Cristo, que habita dentro y fuera de la Iglesia, podía tomar la decisión, en comunión con la misma Iglesia ("nos ha parecido bien al Espíritu santo y a nosotros", Hech 15, 28), sobre cómo hablar con un lenguaje que todos, naciones y culturas, pudieran escuchar y entender en su propia lengua (Hech 2, 8). Invocó un nuevo Pentecostés para que el Espíritu se posara sobre la Iglesia. "Ven Espíritu santo y renueva la faz de tu Iglesia" - ésa fue, al parecer, su oración. No creía que había otra forma de lograr un aggiornamento (puesta al dia) de la Iglesia. Aquí está, el verdadero origen del Vaticano II. Y a eso apuntaba también el concilio.

Además, en la percepción del papa, el aggiornamento no se podía lograr con la declaración de nuevos "dogmas" (en el sentido de definiciones doctrinales), lo que, como insistían algunos, era necesario para frenar la marea de herejías "modernistas", que supuestamente se introducía en la Iglesia. Por el contrario, el aggiornamento sólo se podría conseguir a través de una renovación pastoral, lo que exigía un cambio, tanto actitudinal como estructural, en toda la Iglesia.

Este enfoque era totalmente distinto de lo que habiamos conocido hasta entonces, en la historia de los grandes concilios. La mayoría de éstos, en efecto, habían introducido clarificaciones doctrinales contra tendencias heterodoxas, o reformas institucionales, lo cual dejaba a la Iglesia intacta en sus estructuras. En

1. Sobre el problema de tradiciones y tradición, véase Y. M-J Congar, Tradition and Traditions: An Historical and a Theological Essay, New York, 1966. 
este concilio, sin embargo, el método adoptado por el Espíritu y por toda la Iglesia fue algo sin precedentes: tomaron varias decisiones que, por su naturale$z a$, eran generadoras de crisis y apuntaban a una renovación total, como explicaremos más adelante.

\subsection{La dinámica del concilio}

Teniendo esto en cuenta, el consejo que nos daba Rahner a nosotros, los que pertenecíamos a la nueva generación, iba directo al grano: en lugar de gastar energías en la exégesis de los textos conciliares, deberíamos dejarnos empapar por el espiritu del concilio, introduciéndonos totalmente, mientras se desarrollaba el concilio, en su ethos, de tal manera que - eventualmente-pudiéramos avanzar, a partir de lo que el concilio proponía, desde las perspectivas nuevas, que el mismo abría. No fue diffcil, por supuesto, sumergimos en ese ethos, tal como nos lo pedía Rahner. De hecho, el concilio ya se había convertido en un acontecimiento colosal para el mundo entero. Incluso la prensa secular cubría los debates y las disputas, que configuraron la dinámica de los decretos conciliares, cuando dichos decretos empezaron a tomar su forma actual, en medio de un caos de crisis y compromisos, lo cual incluía intrigas vaticanas e intervenciones papales, por no mencionar campañas difamatorias, que crispaban el ambiente, tanto dentro como fuera del aula magna (la sala principal de la asamblea) ${ }^{2}$. Los medios dieron cuenta de todo ello con descamada lucidez. ¡Y nosotros lo leíamos con insaciable avidez!

Rahner nos pedía que comprendiésemos el concilio no como el "producto final" de un proceso, sino como "proceso en sí mismo". La tarea de nuestra generación, por lo tanto, debía consistir en avanzar hacia delante, desde el lugar en que nos hubiera puesto el Concilio. El Vaticano II, insistía Rahner, no era un punto de llegada, sino i"un punto de partida" (punctum a quo proficiendum est, por decirlo en sus propias palabras)! Dicho de otra manera, nuestra misión era completar la agenda "no escrita" con la teo-praxis correspondiente a su nueva orientación. En lo personal, junto con otros muchos, del consejo de Rahner hice un programa de vida. Esta historia todavfa no ha sido escrita, pero en otro lugar ${ }^{3}$ ya he ofrecido destellos de aquella época de verdadera aventura.

Mi humilde consejo a los que han llegado después de nosotros y no se han familiarizado con el proceso histórico del concilio es que estudien sus enseñanzas con la ayuda de las Acta Concilii (las minutas por así decirlo). Una reproducción a cámara lenta del proceso que generó este concilio puede leerse en Historia del Vaticano II (editado por Giuseppe Alberigo, Orbis y Peters ${ }^{4}$ ), que

2. Cfr. Y. Congar, Called to Life, Crossroad, New York, 1987, p. 34.

3. "Dialogue", NS, XXV-XVI (1998-1999) 265-292.

4. Quienes no tengan acceso a estas fuentes pueden, al menos, ver la parte primera del documental de la $B B C$, en cuatro partes, $A$ bsolute Truth. Ahí se puede ver y escuchar 
- cuando escribo este artículo- ya va por el volumen IV, que cubre el período de septiembre 1964 a septiembre 1965. Si no se tiene en cuenta este transfondo histórico, los textos de los documentos conciliares significarán muy poco. En efecto, en la formulación del mensaje conciliar hay contradicciones menores y también compromisos. Como en la exégesis de la Escritura, tienen que resolverse contextualmente, a la luz de la historia y de los debates y discusiones que marcaron su génesis.

\section{Primera parte: el "concilio" de Jerusalén como precedente}

\subsection{La crisis que exigió una decisión conciliar}

El único precedente que pudiera explicar, de alguna forma, la naturaleza del Vaticano II es el acontecimiento que se describe en Hechos 15, 1-29, al cual desde tiempos recientes se le suele llamar "el [primer] concilio de Jerusalén". El episodio ofrece peculiaridades en consonancia con lo que sabemos del Vaticano II. Soy consciente, por supuesto, que sería temerario considerar ambos "concilios" como equivalentes, en todos sus aspectos. Además, el mismo término concilio sólo análogamente se puede aplicar a la asamblea de Jerusalén. La comparación que vamos a hacer sólo sirve como medida pedagógica para ayudar a los lectores de una nueva generación posconciliar a avanzar de lo conocido a lo desconocido.

Una lectura cuidadosa de lo que se dice en Hechos 15, 1-29 muestra la existencia de una doble crisis, en la Iglesia naciente. La primera fue la crisis ocasionada por la convocatoria de un concilio. La segunda fue la ocasionada por el mismo concilio. La solución, gradual y dolorosa, de la segunda crisis acabó eliminando totalmente la primera, y éste es también el proceder en el origen, el desarrollo y las consecuencias del Vaticano II. S6́lo que en este caso, la segunda crisis no ha sido resuelta todavía, incluso cuatro décadas después, debido a la reacción contraria que, durante el último cuarto de siglo, o más, ha está operando en el centro de la Iglesia. Esto explica por qué la primera crisis todavía está dañando -y como obsesionando - a la Iglesia.

Analicemos la primera crisis, en la Iglesia naciente, de la cual el centro, es decir, la Iglesia de Jerusalén, dichosamente y, por supuesto, comprensiblemente, era ignorante. Los que después fueron enviados al centro (apostoloi), como Pablo y Bernabé, que sí tenfan conocimiento de primera mano de la situación de frontera, informaron que "se estaba cociendo" una crisis en la periferia (Antioquia). La razón era, en parte, que los tradicionalistas del centro, que ya habían visitado la periferia, intentaron imponer su visión rígida ("no hay

a algunos de los arquitectos del concilio (König, Heeley, Küng y otros), que recuerdan en detalle las encrucijadas que precedieron y acompañaron a este acontecimiento realmente único. 
discipulado cristiano sin circuncision") a aquella Iglesia local, con lo cual generaron disputas y disturbios innecesarios, e hicieron necesario que los miembros de la Iglesia de Antioquía enviaran representantes a Jerusalén (Pablo y Bernabé) para resolver el problema.

En el concilio reunido en Jerusalén, para resolver esta crisis, los tradicionalistas insistían en el status quo, a pesar de los informes positivos que los misioneros traían de la frontera (vv. 4-5). Afortunadamente, ocurrió algo que abrió la mente y el corazón del centro: un largo debate y una valiente intervención de Pedro, el lider de toda la Iglesia, quien apeló a su propia experiencia, inspirada por la fe, no sólo de la crisis, sino también de su solución (vv. 6-11). Esto generó una atmósfera muy necesaria de silencio (v. 12), lo cual permitió a Pablo y Bernabé exponer su caso en detalle y con claridad ante la asamblea. Incluso Santiago, el líder de los conservadores, cedió a las exigencias de la periferia, gracias al apoyo de Pedro (vv. 13 -21).

Los pilares de la Iglesia, Pedro, Santiago y Juan, ratificaron la nueva política pastoral, y, como Pablo recordaría más tarde, "sólo que nosotros debíamos tener presentes a los pobres, cosa que he procurado cumplir con todo esmero" (Gal 2, 10). De acuerdo a esa decisión de la asamblea, los pobres tenían prioridad sobre los asuntos prácticas tradicionales. Es importante recordarlo también por lo que toca al Vaticano II. Cuando Juan XXW anunció el concilio, expres6 su sueño de una "Iglesia de todos" especialmente de los pobres.

A esta decisión de la asamblea de Jerusalén siguió un serio intento de lo que hoy llamariamos la recepción de un concilio: a la periferia fueron enviados mensajeros con las buenas noticias, para instruir a las iglesias acerca de la nueva política pastoral (Hech 15, 30-31). Suprimieron toda carga innecesaria; y todo lo que se esperaba de los neo-conversos era que guardaran unas pocas y sencillas costumbres sobre las comidas, que no alienasen a los paganos de los judíos, así como la insistencia general en la moral sexual (Hech 15, 28-29). A estas normas prácticas, adoptadas por los apóstoles, Hechos 16,4 se refiere, técnicamente, como ta dogmata ta kekrimena ton apostolon.

Y aquí podemos ver el significado original que la palabra "dogma" tiene en la Escritura. Con este término se quería indicar una normativa práctica (veáse también Dan 2, 15; Lc 2, 1; Ef 2, 15; Col 2, 14) y no la reformulación doctrinal de una verdad revelada a la cual hay que asentir, bajo pena de excomunión (anathema). La finalidad de aquel concilio no fue "enseñar nuevos dogmas" (en el sentido en que hemos llegado a comprender los dogmas, en los catecismos actuales y en la historia de los últimos concilios), sino proponer nuevas normas exigidas por los signos de aquel tiempo (los dogmas de que hablan los apóstoles). La autoridad de atar y desatar, permitir o prohibir (Mt 18, 18) expresa la comprensión judía de la autoridad durante el primer siglo, es decir, la que tenían los rabinos para decidir qué prácticas debía seguir la comunidad o, usando un 
término judío muy posterior, para "determinar la halakah"s. En Mateo 18, 20, Cristo transfiere esa autoridad [rabínica] a sus discípulos. A esta luz, se puede presumir con seguridad que Hech 15, 28-29 ("nos ha parecido al Espíritu Santo y a nosotros") es un claro ejemplo en el cual los apóstoles y el Espíritu Santo, actuando como co-autoridades enviadas por Cristo a una misión, han determinado la halakah, es decir, propusieron nuevas políticas de práctica pastoral, que en las escrituras son conocidas como dogmata (Hech 16,4).

\subsection{La crisis que originó está decisión conciliar}

Estos dogmata, o "normativas pastorales", que acabamos de mencionar eran, por su naturaleza, generadores de crisis. Con ellos se expresaba una opción tan novedosa que "disentir", se convertiría tanto en el costo como en el medio para la renovación. El abandono de una práctica sacrosanta, que creían sancionada por voluntad divina, así como por una tradición sagrada de veinte siglos (de acuerdo al modo judío de contar el tiempo) podría parecer temerario, si no blasfemo.

Más aún, toda "práctica" es una formulación tácita de una "teoría", lo cual también era verdad de esta nueva práctica, recomendada por el concilio de Jerusalén. Implicaba una nueva postura teológica, es decir, que la observancia ritual de la circuncisión no era necesaria para la salvación; pues "la circuncisión del corazón en el Espíritu" es lo que nos incorpora a la familia de Dios (Rom 2, 29). Y la argumentación fue llevada hasta sus últimas consecuencias lógicas: no sólo la circuncisión, sino toda la observancia legalista de la Torá, de la cual la circuncisión no es más que una parte, es igualmente incapaz de traer la salvación o la justificación, que sólo proviene de la confianza en Cristo Jesús (Gál 2, 15 - 3, 14).

Y las cosas no terminan ahí. Esta reflexión teológica pudo ser aplicada también al rito cristiano del bautismo, en el sentido de que no podía quedar circunscrito a un rito (sacramental), sino que tenía que ser comprendido como "discipulado cristiano", el cual consiste en la inmersión en la muerte (y la resurrección) de Cristo, como argumentará Pablo (Rom 6, 3-4), pues sólo en ese sentido Jesús habló del "bautismo" con relación a sí mismo (Mc 10, 38-39, par.).

En otras palabras, las decisiones pastorales del concilio de Jerusalén provocaron, en las comunidades, una crisis posterior, debido a los cambios actitudinales, así como estructurales, de tales decisiones, que provenían de una comunidad de fe. El libro de los Hechos, de 21,15 en adelante, describe esta segunda crisis ampliamente, sin tapujos y en escandaloso detalle. La carta a los Gálatas apunta a los compromisos que hasta los mismos líderes se vieren forzados a hacer, más tarde, ante la oposición de los tradicionalistas ${ }^{6}$. Lo que provocó la

5. Cfr. David Stem, "Introduction", Jewish New Testament, Jerusalén, 1989, xxiii.

6. Asumo que Gál 2, 11-15 se refiere a la crisis provocada por el concilio más que a la crisis que lo hizo necesario. 
crisis fue el "escándalo", es decir, las consecuencias doctrinales y sociales que la nueva práctica habla generado, en las mentes y en las vidas de los judíos conservadores, creyentes en Cristo.

En la lucha por resolver esta crisis, la recepción del concilio, por parte de los creyentes judios en Cristo, se mezcló con algo todavía más novedoso: la recepción del mensaje de Cristo entre los no-judios de todo el mundo. El cristianismo hubiese quedado reducido a una mera secta judía, o hubiese sido absorbido por el judaísmo, si no hubiese sido por esta decisión del concilio de Jerusalén, generadora de crisis. Hizo posible que el mensaje de Cristo llegase a ser Buena Noticia para todos los hombres y mujeres de buena voluntad, en todos los lugares del mundo. Escribo hoy estas líneas como "un discípulo gentil de Jesús, el mesías judio", precisamente, por aquella decisión del concilio de Jerusalén, que generó una crisis, pero que liberó al evangelio de ser dominado por una nación, una cultura, una lengua, una tradición.

Con gran precisión, Karl Rahner describió la decisión de Jerusalén como una caesura, "un corte claro" con relación a un pasado culturalmente estrecho, y esperaba que el Vaticano II (que según él fue el primer concilio de la "Iglesia universal", en toda la historia) fuese una caesura semejante, es decir, una ruptura radical con occidente?. ¡De hecho, los ministros de frontera de las iglesias locales de las cuatro partes del mundo habían llevado sus esperanzas y temores a la Iglesia universal, reunida en el centro, para que los tomara en cuenta!

El auténtico fruto del concilio Vaticano II tenía que consistir en liberarse de la institución eclesial monolítica, en que se había petrificado la "comunión romana"; es decir, en el cambio estructural que hiciera posible una admirable pluriformidad, en términos de género, raza, cultura y lengua; en breve, que fuera posible la liberación de la Iglesia universal de la dominación de una Iglesia local hiero-patriarcal, la cual durante siglos, se había impuesto sobre las otras como la una y única Iglesia católica (universal).

Hagamos una última observación. El Vaticano II es también el primer concilio desde la asamblea de Jerusalén que tomó decisiones que generaron crisis, lo cual no sólo trajo consigo - aunque con mucho retraso- la caesura del dominio euro-eclesial, como lo observó Rahner, sino que desencadenó una serie de nuevos comienzos, en casi todos los ámbitos de la teología, la espiritualidad, la vida sacramental y la praxis social. Fue un concilio de renovación, no un concilio de reforma.

7. "Toward a Fundamental Theological Interpretation of Vatican II", Theological Studies 40 (diciembre 1979) 716-727. 


\section{Segunda parte: algunas declaraciones del Vaticano II, generadoras de crisis}

\subsection{La naturaleza de una decisión que genera crisis}

Tuve la oportunidad de oír contar a Francoit Houtart el siguiente ejemplo con el cual quería esclarecer lo que significa una decisión, en sí misma, generadora de crisis ${ }^{8}$. Puso como ejemplo hipotético el caso de un club de fútbol, que tenía como tradición incuestionable, que el capitán del equipo fuese también reconocido automáticamente como presidente de ese club de fútbol. En el correr del tiempo, sin embargo, se fueron introduciendo muchos "cambios institucionales", que, en la práctica, sin notarlo, fueron cambiando esta situación. Así, aunque por constitución se mantenía la identidad de un club de fútbol, uno tras otro, se fueron introduciendo otros deportes (tenis de mesa, cricket, volley ball, squash, etc.) como parte de sus actividades. Y estas reformas institucionales no afectaban radicalmente la estructura del club. Este seguía siendo, como siempre, el club de fútbol.

Supongamos ahora que un día los miembros del club se juntan en asamblea, con los poderes que les otorga su constitución, y deciden re-definirse a si mismos como "club de deportes" (en lugar de "club de fútbol"), y definen así la nueva realidad generada por los cambios introducido de forma constitucionalmente válida. Si esto ocurriera, tendríamos un ejemplo de una decisión generadora de crisis. Una vez que esta decisión llega a ser constitucional, imumpe, como un volcán, una crisis imprevisible, que genera trastomos violentos entre sus miembros. Muchos de los no-jugadores de fútbol podrían cuestionar el derecho tradicional del capitán del equipo de fútbol a ser presidente del club, pero que ya no es ahora meramente un club de fútbol - y se cuestionaría también que otros miembros de la directiva reclamasen derechos similares. Habría ocurrido un cambio radical en la auto-comprensión.

Pues bien, esta nueva conciencia desencadenará una masiva crisis de identidad, en los directivos anteriores. Argumentarán que su asamblea legislativa no habfa discutido que los roles y funciones de sus miembros estuviesen sujetos a cambio y que, por lo tanto, exigir cambios en esos roles y funciones sería inconstitucional. Por su parte, el resto de los miembros del club argumentarian, con toda razón, que la re-definición que había tenido lugar implicaba, constitucionalmente, una re-definición de roles y funciones, en la sociedad, que ya había sido redefinida. En medio de este conflicto, algunos de los miembros del club podrán insistir en que no era eso lo que ellos querían decir cuando votaron por el cambio; otros podrán abandonar sus puestos en la directiva e incluso quizás abandonar el club del todo.

8. Fue en uno de los muchos seminarios, llamados FERES, que dirigió en Sri-Lanka durante el período inmediatamente posterior al Vaticano II. 
En conclusión, una decisión que genera crisis y sin la cual no es posible ninguna renovación, no puede alcanzar su objetivo sin forzar a la institución a pasar por un túnel de disensiones y confusión. Los esfuerzos de los renovadores por re-definir los roles y las funciones de sus miembros siempre llevan a pagar un precio: renuncias (funcionarios que, en protesta, abandonan sus puestos) o salidas (miembros que abandonan cismáticamente la institución).

Esta es más o menos la historia del Vaticano II y de lo que ocurrió después. A diferencia, digamos del concilio de Trento, que optó por meras reformas institucionales, el Vaticano II (cuyo propósito era una renovación radical) lanzó a Ia Iglesia a un época tumultuosa de contestación, después de haberla despertado de su "sueño dogmático". Después de todo, quien lo convocó, el buen papa Juan, como en su día lo llamaban con cariño, lo visualizó como un pentecostés. El primer pentecostés fue un acontecimiento tumultuoso, que tomó la forma de "viento violento" y "lenguas de fuego" (Hech 2, 2-3). La novedad fue tan radical que, a los ojos de quienes no habían despertado, los discípulos les parecían una pandilla de borrachos delirantes (v.13). Pero el resultado fue sorprendente: lo que solía ser una comunidad de creyentes de la misma raza, lengua y cultura, se dio a entender y se hizo creíble a todas las naciones, y evolucionó gradualmente, hasta llegar a ser una Iglesia verdaderamente católica, que plantó sus raíces, en una diversidad de culturas.

Para usar la misma analogía, el Vaticano II fue un pentecostés de violenta renovación, gracias a sus decisiones de largo alcance, en las cuales se hacía presente el imperativo implícito de cambiar toda la Iglesia, estructural y actitudinalmente con respecto a su modo de vida y liturgia, su ministerio y teologfa, su estructura y gobierno, de modo que fuera así un testimonio creble y un signo comprensible ante el mundo contemporáneo.

El concilio tomó más de una decisión de esas que generan crisis. Algunas de ellas, para usar la jerga latina, usada frecuentemente por los padres del concilio, fueron hechas ad extra, es decir, con la mirada puesta en el mundo fuera de los límites visibles de la Iglesia. Otras fueron resultado de una mirada al interior de la Iglesia, ad intra. A continuación analizaré en detalle una re-definición ad intra, y después mencionaré, más brevemente, otras dos.

\subsection{El Vaticano I: tres ejemplos de decisiones conciliares que generaron crisis}

\subsubsection{Re-definición implícita de roles y funciones}

El cambio más crítico que llevó a cabo la autoridad del concilio, en la línea de los renovadores, fue su re-definición implicita de roles y funciones (papa, obispos, sacerdotes, ordenes religiosas, nuncios papales e incluso el Vaticano). Esa re-definición de roles y funciones no fue algo buscado explícitamente, sino 
el resultado indirecto de la decisión de re-definir la Iglesia como el pueblo de Dios, en Lumen Gentium 7, citando la Primera Carta de Pedro - decisión generadora de crisis, en verdad. En otras palabras, la Iglesia, que tradicionalmente se habla definido a sí misma en términos de su jerarquía androcrática (términos griegos para decir detentadores-de-poder sagrado y dominado por varones) se empezaba a percibir a sí misma como una comunidad inclusiva del único pueblo sacerdotal, el laos (de ahí la palabra "laicos y laicas")'. Esta invitación a nivelar lo que era una pirámide, construida y consolidada durante un período de casi dos mil años, generó una crisis, en al menos cuatro áreas.

La primera víctima de esta decisión fue el sacerdocio clerical masculino. La reapropiación de la fe neotestamentaria en el único sacerdocio de Cristo, tomados a una la cabeza y los miembros de la Iglesia, volvió a poner al ministerio clerical en su lugar original de presbiterado.

El presbitero, presbyter, ejercía una función de liderazgo no-cúltica dentro del único pueblo de Dios (el laos, los laicos ${ }^{10}$ ) sacerdotal o cúltico, que verdaderamente constituía la comunidad litúrgica de co-sacerdoles y co-víctimas, unidas al Cristo sacerdote-víctima. Las reformas litúrgicas posconciliares trataron, por lo tanto, de respetar el lenguaje, las costumbres y la función activa del pueblo.

De esa forma, la tradicional línea de demarcación, que separaba claramente a los laicos como los no-sacerdotes y al presbítero como "el sacerdote", con un status muy por encima de los laicos, parecla desvanecerse. Muchos "sacerdotes", formados en los seminarios antes del Vaticano II, se preguntaban: "Entonces, ¿qué es lo que mi ordenación sacerdotal me otorgó a mí que no tienen ya los laicos?". Se estaba gestando una crisis de identidad ante el nuevo contorno de los roles y las funciones de los ministros, la cual iba tomando forma en el contexto de la eclesiología conciliar. Una inevitable consecuencia de esta decisión fue una crisis de salida en masa de sacerdotes, en la década del post-conciliar.

La segunda víctima fueron los miembros de las congregaciones religiosas, quienes habían profesado vivir según los consejos evangélicos. Habían sido formados en la idea de que pertenecían a una clase de buscadores-de-perfección, exentos de las distracciones seculares de los laicos. El concilio, por el contrario, percibió que la santidad a la cual la Iglesia (es decir, el pueblo de Dios) es llamada por Dios, es universal, no es una santidad estratificada jerárquicamente (de arriba a abajo), sino diversificada carismáticamente, dentro de una única llamada universal, que reciben todos los cristianos como parte de su sacerdocio

9. Este "pequeño paso" dado por los padres conciliares se convirtió en "paso de gigante" para la toralidad de la Iglesia, y abrió la puerta a un proceso para que, en futuros sínodos, "madres" del concilio pudieran tomar decisiones.

10. La palabra laicos - laicidad - , sin embargo, en los documentos conciliares es usada en un sentido poco preciso, y a menudo como contraparte de ministerio ordenado. 
bautismal. La obediencia evangélica ("sólo Dios") y la pobreza evangélica ("ningún otro Dios"), que resumen la espiritualidad de todos los creyentes, proclamada según el primer mandamiento del primer testamento y el sermón del monte del segundo testamento, conllevan un compromiso indiviso al servicio de Dios y del prójimo, según la propia vocación (es decir, la castidad tanto marital como célibe). Todo ello es expresión del compromiso bautismal".

“¿Entonces, qué me dieron mis votos religiosos que no había recibido ya antes en mi bautismo?", era la pregunta en que afloraba la crisis de identidad de quienes pensaban que el matrimonio era una concesión del creador a la gente ordinaria, debilitada por la came, mientras que los célibes habían sido elevados a la vida superior del Espíritu. La salida en masa, en los sesenta, de hombres y mujeres consagrados, que optaron a menudo por la vida de familia, fue otra consecuencia inevitable de la re-definición de roles y funciones dentro de la Iglesia.

En tercer lugar, también fue causa de conflictos la diferencia entre el obispo ("supervisor") y el presbítero ("anciano"), se la entienda como meramente jurisdiccional o también sacramental. El problema ya salió a la luz durante el concilio, y la solución que éste da en sus documentos - al no ir a la raíz y abordarlo como para salir del paso- todavía se discute acaloradamente. Recuerdo que, en algunas entrevistas, algunos obispos se mostraron contrarios a esta supuesta confusión de roles. Pensaban, por ejemplo, que la nueva liturgia, que propiciaba el concilio, permitía a los sacerdotes sentarse en un "trono" para presidir la comunidad litúrgica, lo cual, tradicionalmente, así pensaban, era una prerrogativa específicamente episcopal. Incluso pequeñeces como ésta hicieron que algunos jerarcas perdieran la compostura.

Por último, el cambio más revolucionario que se esperaba del concilio era la re-definición de los límites entre primado del papa y colegialidad de los obispos $-y$ hay que estar claros sobre la transcendencia del terna. En efecto, ante los cristianos separados, la unión de las iglesias, o ecumenismo, depende de la credibilidad que proyecta la Iglesia de Roma, en su manera de relacionarse con otras iglesias locales, las cuales ya están en comunión con ella. Esto implica redefinir la función de los dicasterios vaticanos y de las nunciaturas como meros instrumentos de un gobierno de la Iglesia que se ejerce colegialmente, a la vez por el papado y el episcopado, en lugar de seguir operando como un poder autocrático, que invoca la autoridad de la sede primacial de Roma para controlar a los obispos y sus iglesias. Y ello, a pesar de la declaración conciliar de que todas las iglesias locales son cuerpos que se autogobiernan (Orientarium eclesiarium 5).

11. Para una elaboración teológica de esta comprensión de los votos religiosos después del Vaticano I, véase mi libro Fire and Water, Basic Issues in Asian Buddhism and Christianity, Nueva York, 1996, caps. 16 y 18; véase también "Chastity as Total Consecration to Service", Vidyajyoti Journal of Theological Reflection, Vol. LVIII, No. 9, (septiembre 1994) 545-558. 
Y de aquí surgen dos preguntas. La primera es si los sínodos romanos deben seguir siendo como hasta ahora, es decir, una mera institución papal, en la cual los obispos tienen sólo una función consultiva. La segunda es si sirven como foro donde se comparte el poder, pero sólo del papado y del episcopado, sin ningún mecanismo que asegure que todo el pueblo de Dios -que representa a las iglesias locales (y sin discriminación de género) - forme parte del proceso de la toma de decisiones ${ }^{12}$.

\subsubsection{Una redefinición ad extra}

En una decisión de tipo ad extra, el concilio redefinió la Iglesia como sacramento universal de salvación. Esta sencilla fómula, generadora de crisis, implicaba una misionología revolucionaria, que relativizaba a la Iglesia en relación al reino de Dios, lo que polarizaba a los teólogos, por lo que toca a la comprensión del mandato-misión de Jesús resucitado (Mt 28, 19) y del rol del misionero tradicional. El Vaticano II, al cual se responsabilizó del éxodo de sacerdotes y religiosos, también fue criticado por generar crisis en las misiones.

Como en el ejemplo anterior, lo que pretendía realmente era invitar a redefinir las "misiones", de acuerdo a las nuevas perspectivas y a adquirir una nueva visión de la "evangelización". Esta nueva visión condujo a una teología de las religiones completamente nueva. De hecho, los té́logos asiáticos, así como la FABC, han ido elaborando esta misionología implícita, en la redefinición que acabamos de mencionar. Y de los apóstoles de frontera, se escucha en Asia la llamada a re-interpretar la noción de "conversión" - lo que exige una nueva política misionera-, tal como, en su tiempo, Jenusalén la escuchó de Pablo y Bernabé. En este contexto, el conflicto centro-periferia está todavía por resolver, como se puede deducir de lo que dice la Dominus Jesus, publicada por la Congregación de la Doctrina de la fe, y de las reacciones en todo el mundo - así como del caso Jaques Dupuis ${ }^{13}$.

\subsubsection{Dei Verbum}

La constitución Dei Verbum es otro documento con potencial para generar crisis. Tuvo un profundo significado, y supuso una diferente autocomprensión de la Iglesia católica, en relación con otras iglesias (separadas). Así como la Iglesia había quedado relativizada, al ponerse en relación con el reino de Dios, como hemos visto, así ahora, no sólo a la Iglesia, sino incluso a su magisterio, se le niega

12. Vease Aloysius Pieris, "Two Things There Are Your Holiness: Suggestions for the Next Pope's Agenda in Line with John Paul II 's Invitation in Ut unum sint", East Asian Pastoral Review, $41 / 3$ (abril 2004) 288-309.

13. Sobre esto he escrito en "Roman Catholic Perception of Other Churches and Other Religions after Vatican's Dominus Jesus", East Asian Pastoral Review, 38 (2001) 207-230. 
explícitamente cualquier autoridad sobre la palabra de Dios, a la cual tiene que subordinarse (magisterium non supra verbum Dei est, sed eidem ministrat). A pesar de sus muchos compromisos y limitaciones, este documento entronizo audazmente la palabra de Dios en el centro de la vida de la Iglesia ${ }^{14}$. Por supuesto, algunos acusaron al concilio de haberse echado en brazos del protestantismo, pero otros (por ejemplo, la revista Etude de los jesuitas franceses) se atrevieron a celebrar la promulgación de la Dei Verbum como el final de la contrarreforma anti-protestante ${ }^{15}$.

La primera víctima fue la teología escolástica tradicional de la época tridentina, que durante el concilio tenía muy elocuentes abogados entre los curiales. Stanislas Lyonnet, del Instituto Bíblico de Roma - obligado por el Santo Oficio (así se llarnaba antes, Congregación para la Doctrina de la $\mathrm{Fe}$ ahora) a dejar de enseñar, y restituido más tarde a su cátedra por Pablo VI- era libre, por fin, para enseñar aquello por lo que antes había sido censurado. Sus conferencias, ampliamente escuchadas en diferentes lugares, en la década posconciliar, pusieron de relieve el agudo contraste entre el mensaje bíblico, expresado en el idioma semítico propio, y las distorsiones helenistas de las que había sido objeto, en la teología tradicional occidental ${ }^{16}$. Surgi6 un movimiento universal para revisar la herencia cristiana, a la luz de la soteriología bßlica.

Esta soteriología gira alrededor de la alianza de Dios con los esclavos oprimidos de Egipto, alianza que se hizo nueva en Jesús, quien es, al mismo tiempo, Dios y el Pobre, en una persona. El rol de los pobres en la salvación del mundo, junto con la dimensión "intramundana" de la espiritualidad bíblica, comenzó a desafiar el modelo tradicional de hacer teología. La iglesia de los pobres, vislumbrada por Juan XXIII, comenz6 sus dolores de parto. Los pobres, que son la "contraparte" de la alianza de Yahve, llegaron a ser reverenciados y servidos como los sujetos de la historia En lo personal, he de decir que el mejor fruto de esta decisión, que generaba una gran crisis, fue la reologia de la liberación. La crearon los pobres de América Latina, en el proceso de escuchar y responder a la Palabra, tal como la escuchaban en las Escrituras y en la historia de su tiempo. Este fue el descubrimiento - llegado con muchísimo retraso- de una altemativa a la teología de dominación, fruto de una escolástica no bßblica. Continúa todavía la polarización entre las dos teologías, y la crisis no ha desaparecido, como se puede inferir de, al menos, dos instrucciones de la Congregación de la Doctrina de la Fe sobre la teología de la liberación.

14. Vease Enzio Bianchi, "The Centrality of the Word of God", en G. Alberigo ef al., The Reception of Vatican II, Washington D.C., 1987, pp. I15-136.

15. Congar, Called to Life, p. 35.

16. Quedó ampliamente demostrado en las conferencias que tuvo en 1968, ante la Asociación Biblica Italiana, publicadas después como /l Nuovo Tesłamento alla luce dell' Antico, Brescia, 1971. 
Esa soteriología bíblica, surgida en América Latina, ha tenido también un impacto profundo y permanente, en muchos teólogos de Asia, donde hemos visto el surgimiento de diversas formas de teologías políticas ${ }^{17}$. De acuerdo a la realidad específica de Asia, sus téblogos hicieron de la Dei Verbum un punto de partida para el encuentro cristiano con la Palabra en sus religiones - numerosas - y con sus propias Escrituras ${ }^{18}$.

\section{Conclusión: el arte de resolver las crisis posconciliares}

\subsection{La solución de las crisis, en la época anterior al Vaticano II}

La historia da cuenta de muchos movimientos reformadores que afectaron a la Iglesia, en el período anterior al Vaticano II. El modo de proceder - como quedará claro en los ejemplos que aduciremos - puede ser descrito como dialéctico. La tesis consiste en una crisis de liderazgo, en la Iglesia institucional, y se trata de crisis porque el centro suele verla como una crisis de obediencia más que como una crisis sobre su propia credibilidad. El deseo de cambio se convierte, entonces, en un movimiento que se organiza en los márgenes de la Iglesia, donde los "apostoles de frontera" afrontan los desafíos de la palabra que se pronuncia fuera de los confines visibles de ésta. La antítesis es una reacción desesperada y desproporcionada, en contra de la actitud del centro, que puede tomar la forma de un movimiento de "ruptura". Entonces, llega la síntesis: personas o grupos de los márgenes vuelven a llevar al centro los elementos positivos del movimiento centrífugo. En ese caso, la integración centrípeta del movimiento de ruptura temina como una reforma aceptada por la institución, aunque ella misma permanece estructuralmente incambiada. De ahí que una "corriente renovadora", que siempre tiene su origen en la periferia, eventualmente pueda ser bautizada por la institución de la Iglesia como "movimiento de reforma".

El primer ejemplo del cual se tiene noticia es el movimiento del desierto, en el siglo IV. Ya en la época anterior a Constantino, muchos grupos no cristianos, como los estoicos, habían empezado a rechazar lo que el Apocalipsis describe como la bestia atractiva: el modo romano imperial de ser, pensar, vivir, hacer y organizarse. Y a los cristianos les había avisado el maestro, "no sea así entre ustedes" (Lc 22, 25-27), lo que quizás apuntaba a las marchas y desfiles de los oficiales romanos, con gran pompa y vestidos de púrpura. Cuando también el cristianismo sucumbió a esa tentación, incluso los santos sacramentos se fueron convirtiendo poco a poco en aparato a control remoto de un orden clericalizado de

17. Documentación sobre estas teologlas se puede encontrar en A. Pieris, "Political Theologies in Asia"; el capitulo 18 ha sido reproducido en Peter Scott y William Cavanaugh, The Blackwell Companion to Political Theology, 2004, pp. 256-269.

18. Véase, A. Pieris, "Christhood of Jesus and the Discipleship of Mary. An Asian Perspective", Logos 39 (2000) 102ss. 
"detentadores de poder sagrado" (jerarcas), revestidos de esplendor imperial $-\mathrm{y}$ ellos eran los únicos mediadores de la salvación para los laicos. La crftica, por supuesto, vino de los márgenes de la misma Iglesia. Tuvo lugar una estampida hacia el desierto, en busca de un cristianismo auténtico. Fue un movimiento laico, que despreciaba con desdén el ritual en que habían degenerado los sacramentos y el clericalismo a que había sido reducido el presbiterado. Afortunadamente, sin embargo, personas clarividentes, como Pacomio, Basilio y Benito, mucho más tarde, crearon una comunión cenobítica del individualismo eremítico, y reformaron la Iglesia, creando dentro de su estructura un lugar para la vida monástica laical. Era la contraparte dialéctica de la jerarquía.

La historia se repite en el caso de los valdenses, que rompieron con una Iglesia escandalosamente rica, seducida por el capitalismo mercantil emergente. Predicaron el evangelio a los pobres, con los que formaron comunidades. Estas comunidades desafiaron a la Iglesia romana con tal eficacia que hasta sus líderes se ablandaron de su anterior dureza. Estos acabaron por recibir, en Francisco de Asís, una versión del movimiento, que ya era eclesiásticamente aceptable. Lo que la institución aceptó con las órdenes mendicantes era una reforma.

La comupción en las filas de la Iglesia, en el siglo XVI, produjo otro ejemplo semejante. En 1536, Pablo III nombró una comisión para preparar un memorando en el que admitía, con franqueza poco usual, la corrupción del estamento clerical a gran escala. Como reacción a esta crisis, el movimiento de ruptura más agudo fue la "revuelta protestante". Pero también en los márgenes de la Iglesia, fermentaba la protesta, en las obras de Erasmo, Luis Vives, Melancton, Savonarola, por mencionar algunos. En varios lugares de Europa, benedictinos y franciscanos intentaron la apropiación centrípeta de movimientos centrífugos. La devotio moderna fue uno de tales movimientos. Lo que Ignacio hizo con la orden de los jesuitas no fue una contrarreforma, sino un proyecto de renovación personal, o "re-conversión" de los católicos, al auténtico seguimiento de Jesús. Esto es lo que en el latín de los primeros escritos de los jesuitas significaba reformatio, aunque con el uso del término en Trento, se designaban cambios legislativos, decretados por la jerarquía, por lo que toca al gobiemo de la Iglesia' ${ }^{19}$.

En todos estos ejemplos, una renovación radical, que siempre irrumpe violentamente en la periferia, creando con frecuencia rupturas con el centro, es reapropiada por éste como una reforma institucional. Este es el método clásico para resolver no sólo una crisis institucional, provocada por un movimiento renovador anti-institucional, que tiene lugar en la periferia, sino también para integrar en la institución la crisis que, en sí mismo, expresa tal movimiento renovador.

19. Cfr. J. W. O'Malley, "Attitudes of the Early Jesuits towards Misbelievers", The Way Supplement 68 (1990) 64-65. 
En este contexto, la novedad del Vaticano II consiste en la opción a abandonar este modo de proceder, muy trillado a lo largo de la historia. El conflicto centro-periferia (o el conflicto altura-base, en la estructura piramidal de la Iglesia, tal como hoy existe), en los años posconciliares es, en parte, el resultado de que el centro no reconoce la diferencia entre el modelo de renovación preconciliar y el conciliar. La mentalidad curial de la Iglesia romana en todo este asunto, la articula bien el mismo Ratzinger: "no se debe olvidar que todo concilio es ante todo una reforma de la 'cúpula' que después debe extenderse a la base de los fieles"

Haciendo uso de lenguaje piramidal "cúpula" y "base" (lenguaje que abandonó el concilio al re-definir la Iglesia como pueblo de Dios, pero que continúa siendo válido en una Iglesia que todavía no ha abrazado la renovación que esperaba el concilio), Ratzinger hace aquí una generalización que no sólo no logra distinguir entre reforma institucional (que se mueve de la cúpula a la base, para usar su propio lenguaje), por una parte, y renovación radical (cuyo movimiento va de la base a la cúpula), por otra, sino que se niega a ver la diferencia entre el Vaticano II y los concilios anteriores, por lo que toca a reformas, rechazando explícitamente la interpretación de Rahner del Vaticano II como caesura ${ }^{2 l}$.

\subsection{Cómo resolver la crisis pos-conciliar, en el espíritu del Vaticano II}

La singularidad del Vaticano II consistí en que, tanto en su origen como en su desarrollo y conclusiones, toda la Iglesia se entusiasmó con una renovación radical más que con una mera reforma institucional. Renovación significa un movimiento de la periferia al centro (o de la base a la altura), mientras que reforma significa un movimiento que fluye del centro a la periferia (o de la altura a la base). Una es tersa y suave, la otra es tormentosa. El hecho de que en los documentos del concilio aparezcan tantas decisiones que realmente generan crisis es una muestra de su opción por una renovación, que, por su naturaleza, es un fenómeno de la periferia que llega, de modo avasallador, hasta el centro. De ahí que la opción del concilio por una renovación, en el centro mismo de la Iglesia, echando mano de decisiones que iban a generar crisis, esconde una agenda no escrita, que debe ser descubierta y puesta en práctica, en la periferia.

El compromiso por mantener el ímpetu de esta renovación, que ocurre en las fronteras de la Iglesia, eso es, precisamente, lo que para nosotros significa fidelidad al concilio y recepción del concilio. El centro siempre tiende a volver al modelo de reforma (como lo expresa con toda claridad la interpretación de Ratzinger, que hemos citado), lo cual debe ser siempre puesto en cuestión, si se quiere respetar en verdad la agenda renovadora del concilio.

20. Vitorrio Messori, The Ratzinger Report, An Exclusive Interview on the State of the Church, San Francisco, 1985, p. 42.

21. Ibid., pp. 35, 113. 
Nótese, pues, la diferencia entre ambos modelos. En el modelo clásico, descrito más arriba, la renovación ha sido impuesta al centro por la periferia y, eventualmente, ha sido recibida por el centro como una reforma. En el caso del Vaticano II, se revierte el proceso. Las iniciativas surgidas en la periferia son recibidas oficialmente por el centro como su propia agenda, no escrita, para la renovación. Las decisiones del centro son, por lo tanto, por su propia naturaleza, generadoras de crisis, pues la diversidad existente en la periferia no permite al centro "legislar la renovación". Esto serfa una contradictio in terminis. Lo que es legislado universalmente, no puede ser renovación, sino sólo reforma. La conclusión es que los cristianos, en sus propios lugares, son llamados por la suprema autoridad del concilio ecuménico a tomar iniciativas locales y a convertirse en "sacramento de salvación", en el contexto sociocultural donde han sido puestos por la providencia divina.

Si el centro y la periferia no se ponen de acuerdo en esto, continuará el actual conflicto entre ambos. No es una excusa para abandonar el programa de renovación previsto por el concilio, pero hay que estar claros sobre el contexto real, en el cual tiene que fraguar la renovación. El centro puede ser influenciado por antireformadores, que hoy están horrorizados por la re-definición de los roles y las funciones tradicionales, así como por el cambio de paradigma, que les parece casi herético. La protesta de estos grupos puede forzar a que el centro capitule, y el caso Lefebvre lo ilustra. Pablo VI excomulgó a esa facción de dentro de la Iglesia, por no aceptar el espíritu de renovación del concilio; pero el centro no tardó mucho en verse desgarrado entre la necesidad de la renovación y el riesgo de cisma.

A pesar de que el centro ha dado, en varias ocasiones, una vuelta atrás, como se nota en muchos decretos y advertencias reformistas (sobre teología de la liberación, la meditación oriental y, recientemente, sobre la liturgia), la puesta en práctica de la agenda no escrita del concilio está, evidentemente, en la periferia, y prosigue no en forma de desafío cismático, sino como ejercicio de la fe, en el espíritu que convocó el Vaticano II, y como acto de fidelidad a sus decisiones generadoras de crisis.

Un ejemplo. El documento vaticano Redemptionis sacramentum, como otros de este tipo que ya hemos mencionado, es una respuesta reformista al proceso de renovación, que está ocurriendo en las fronteras de la Iglesia. Lo que para unos aparece como un abuso litúrgico, para otros es una renovación litúrgica, como se puede ver en la contestación a este documento por parte de la periferia ${ }^{22}$.

22. Véase, por ejemplo, "Diritto di assenso: Le communita christiane popolari di Granada contro il documento sugli abusi liturgici", Adista 50 (anno XXXVII) supl. al número 5784, 3 de julio (2004) 14-15. Véase también A. Pieris, "A Liturgical Anticipation of a Domination-Free Church: The Liberating Story of an Asian Eucharist", en B. Silva et. al., (editores), Vision for the Furure: Essays in Honour of Tissa Balasuriya, CSR, Colombo, 1997, pp. 69-82; aparecido tambien en The Month, (noviembre 2000) 428-435. 
Esto significa que el conflicto centro-periferia se tiene que resolver en la periferia, pues sólo en ella puede subsistir un movimiento de renovación, sin acabar domesticado como mera reforma. La supervivencia del proyecto renovador del concilio depende no sólo de las iglesias locales de la periferia, sino de la realidad de periferia de esas iglesias locales. La que es realmente frontera, en las iglesias de frontera, tiene un papel muy importante que jugar en hacer explicito lo que el concilio dejó implícito, es decir, completar su agenda no escrita.

En el contexto del conflicto centro-periferia, podemos ver dos tipos de movimientos de ruptura, muy diferentes de los que hemos descrito antes en 4.1. El primero es un movimiento cismático, como el de los lefebvristas, que rechazaron el Vaticano II como obra de herejes modemistas, aunque aquéllos tengan simpatizantes también en el centro. En el otro extremo, del fracaso en la implementación del Vaticano II surge un movimiento de ruptura. Estoy aludiendo a la estampida de católicos a "iglesias" de sectas fundamentalistas. Este fenómeno apunta al fracaso de parte de las iglesias catolicas locales para renovar todos los aspectos de la vida eclesiástica, de acuerdo con el Vaticano II. Recordemos los siguientes aspectos: reorganización de sus ministerios, re-configuración de la vida del pueblo sobre la base de las Sagradas Escrituras, celebración de liturgias que hablan desde y hacia lo profundo del Espíritu, que está operante en el día a día del pueblo, hacer transparentes los valores evangélicos, en el liderazgo eclesial, etc. Sólo hay una respuesta a este problema: la perseverancia inclaudicable en la ejecución de la agenda no escrita del concilio.

Esta agenda no escrita permanecerá con nosotros como un legado perenne. El proceso de renovación que con ella se ofrece a la Iglesia no tiene fin. En sus documentos, podemos escuchar una y otra vez la llamada a una renovación sin pausa (renovare non desinat) y el uso frecuente de los siguientes verbos latinos, renovare, reformare, purificare y mundare, cualificados por expresiones como continuo (continuamente), incessanter (sin cesar), perennis (perpetua), indesinenter (ininterrumpidamente), de die in diem (día sí y día no), etc ${ }^{23}$.

El Vaticano II es, por lo tanto, una gran aventura, en la cual tienen que embarcarse todas las nuevas generaciones de católicos, hasta que la renovación permanente se convierta en nuestra segunda naturaleza, y de esa forma, deje de ser una fuente de conflictos entre el centro y la periferia. Si los sínodos "romanos" se re-organizan como un foro, siempre a mano, al servicio de esta agenda, incesantemente renovadora, tal como lo he sugerido antes, entonces el Vaticano II bien pudiera ser un concilio permanente y, consecuentemente, el último de los concilios.

23. Véase $L G 7,8,9,11,15 ; U R 4,6 ; G S 21$, etc. 